\title{
BIM FOR EXISTING HERITAGE: FROM 3D INTEGRATED SURVEY TO PARAMETRIC MODELING FOR REFURBISHMENT AND MANAGEMENT
}

\author{
N. Tasselli ${ }^{1}$, F. Maietti ${ }^{1 *}$ \\ ${ }^{1}$ University of Ferrara, Department of Architecture, Italy, (tssncl, mttfrc)@unife.it
}

\section{Commission II}

KEY WORDS: Existing Heritage, Digital Survey, Modelling, BIM, As-Built, Refurbishment.

\begin{abstract}
The research is aimed at developing an integrated methodology based on digital tools to support professionals working on existing buildings using BIM - Building Information Modeling methodologies, combining digitization (As-Built) with the growing need for refurbishment in an integrated supply chain perspective. The focus is the XX century heritage in Emilia-Romagna, to respond to a need for widespread redevelopment of existing assets, fostering innovation in the use of advanced digital tools and innovative materials for the redevelopment process. One of the research objectives is to include all actors involved in the building renovation process in developing and managing the BIM model. The main challenge is the complexity of the process, which requires a planned, coordinated, and synchronised effort from all the involved actors. To foster an inclusive approach, the research methodology proposes simplified tools and procedures, designed to allow a gradual transition into the BIM methodology. The development of BIM Smart Packages, which combine the needs of all the actors involved in the refurbishment process and those who have to produce and trade integrated solutions, can increase stakeholders' interest in investing in the digitisation of the intervention process.
\end{abstract}

\section{INTRODUCTION}

\subsection{Overall framework}

The paper focuses on possible innovative approaches in the application of BIM - Building Information Modeling to the existing built heritage, in particular for refurbishment, regeneration and management purposes. The scope of the research is bounded by 20th century heritage in the EmiliaRomagna region; this is to respond to a need for widespread redevelopment of existing assets, which has emerged from specific studies concerning the construction sector (S3, 2021), and to deepen some studies related to innovation processes in the practice of renovation.

Including global challenges from programmes as Horizon Europe (Horizon Europe, 2021) or the Green Deal (European Commission, 2021), priority issues such as digitisation, territorial heritage and regional identity and open innovation are considered to be at the centre of future actions within the construction sector.

Digitisation is both a social trend and a technological priority at international, national and regional level, involving processes, products and services and requiring specific skills (European Commission, 2019).

Within the Regional Research and Innovation Strategy for Smart Specialisation 2021-2027 (S3), digitisation focuses on data throughout its lifecycle: survey, processing, integration, transfer, archiving, making it necessary to use platforms, models and applications for data and processes interoperability, and the implementation of new innovative services. The use of Digital Twin from support in industrial plant design applications to facility management (Jouan and Hallot, 2020), management of cultural heritage (La Russa and Santagati, 2020) or entire cities (Bianchini et al., 2021), is an example of the transfer and customisation of digitisation models across sectors. The introduction and extensive use of integrated digital tools for building and space design, site management and maintenance ("smart" construction site, BIM, predictive monitoring and maintenance, IOT) are part of this development direction. The priorities are AI - Artificial Intelligence applications (Grilli and Remondino, 2019), High Performance Computing, Cybersecurity together with the development of widespread Advanced Digital Skills.

Within the regional S3, the main innovation directions include acquisition, archiving, monitoring, restoration, integrated conservation, management and enhancement of the tangible and intangible heritage and its digitisation (Grilli and Remondino, 2020), including new technologies, advanced methodologies, new materials and AI applications (Teruggi et al., 2021) and the use of big data for risk prevention and optimisation (Harirchian et al., 2020). The need to provide more advanced tools for the conservation process is a crucial issue given the huge availability of assets, the need to increase knowledge and ensure their protection and the positive effects (economic, social, cultural significance) that these assets represent for the regional and national context. These advanced tools include the integration of data to facilitate the careful monitoring of assets and their integrated management.

Regarding existing buildings, not only historical but also modern and contemporary, the topics of greatest interest include digital technologies applied to eBIM (existing BIM), advanced 3D models, predictive maintenance of the built heritage (Achille et al., 2018) and innovation in technological approaches to diagnostics.

The advancement of these procedures can contribute to a faster data acquisition, even in emergency condition, and to a more efficient building site management, to the development of new materials, to the regeneration and assessment of the built heritage and to a data management able to foster digitisation processes and a more efficient data sharing among authorities and operators/professionals.

The paper aims to face the topic of 3D virtual reconstruction and visualization of complex architectures according to two main meanings: complex architectures (existing assets, changed 
over time, characterised by mixed and layered structures), and complexity of information management (Carnevali et al., 2019). Smart 3D reconstructions, modelling, accessing and understanding of digital environments from multiple data sources are among the main drivers to innovate the use of BIM applied to existing heritage.
The connection between redevelopment needs, documentation and intervention procedures through digital technologies is the focus of this research.

The research indeed deals with the integration between digital survey, design workflows made in a BIM environment and construction systems designed for the intervention on the existing built asset (Fassi et al., 2015).

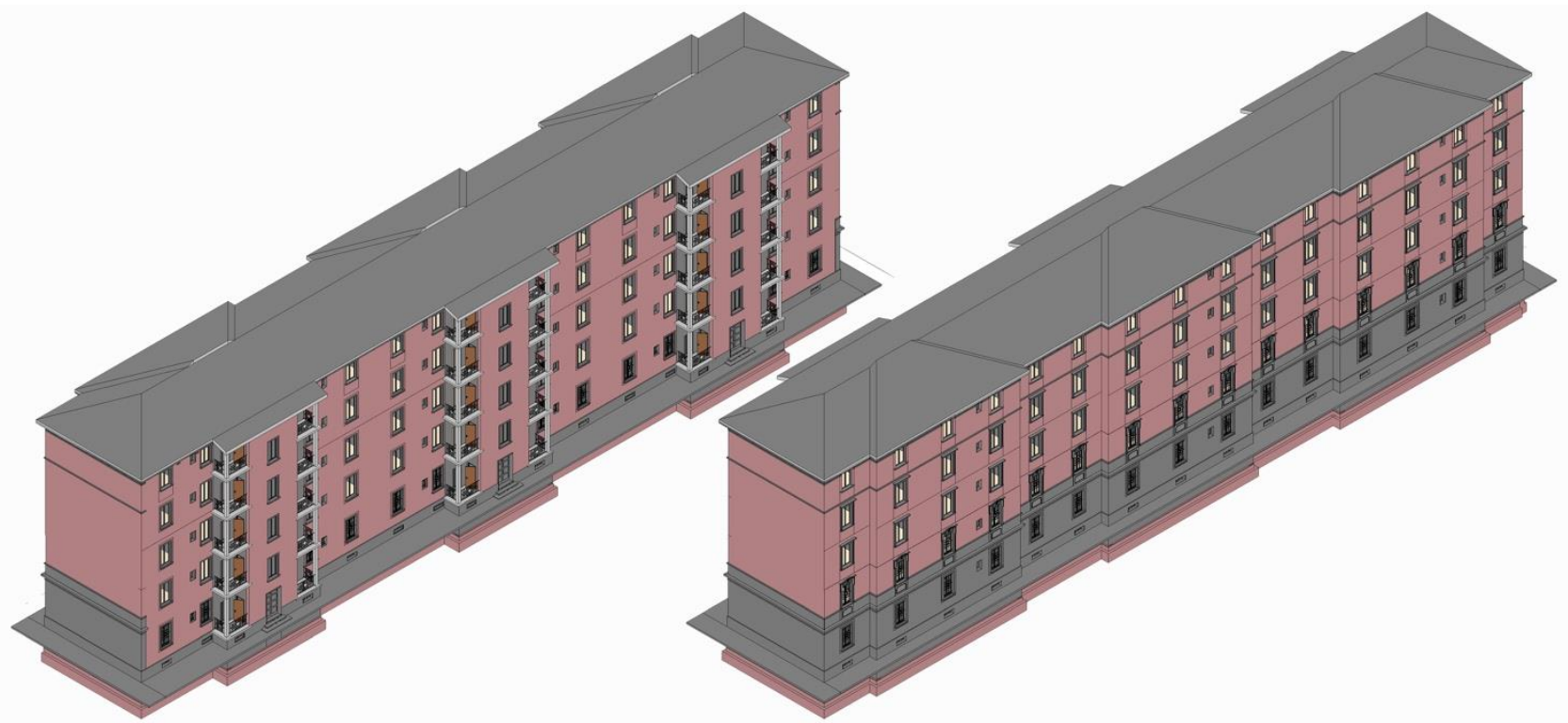

Figure 1. Parametric model developed in a BIM environment, of one of the buildings digitized as a case study, a residential building of the first half of the 20th century in Bologna.

\subsection{Research scenario}

Built during the twentieth century, the existing built heritage represents a substantial component of the entire building stock in the Emilia-Romagna territory. These buildings (Fig. 1) were constructed to provide housing, facilities, and workplaces during the industrial and tertiary expansion. In terms of the building process, during the first part of the 20th century, there was a transition from handicraft production to an industrial one. This transition influenced both construction techniques and building components. In this period, there was a progressive standardization of construction elements, gradually overcoming the use of various local standards, a legacy of traditional building practices, in favour of modern unified standards (Piano Gescal, Legge 6 1963).

The new buildings were designed using a mix of traditional materials (vaulted ceilings, Bolognese bricks) and modern materials (UNI brick, prestressed beams), adopting innovative technologies for that period to increase production and construction speed, often neglecting building quality.

The building expansion from the first part of the 20th century up to the 1960s redesigned the urban scenario for decades. Today, many of the buildings constructed in that period are located in central areas of high speculative interest (Cresme, 2021).

Many buildings constructed during this period are still widely used, and over the years, they have undergone functional upgrading and maintenance to extend their lifespan. Anyway, nowadays these buildings need substantial upgrading to make them safe and energy-efficient according to current building standards (Daniotti et al., 2021).

Seismic safety, accessibility and energy efficiency are the main drivers behind the regeneration of buildings designed with other priorities.

\section{RELATED WORKS}

\subsection{State of the Art and related research activities}

Nowadays, the research scenario in the field of BIM digitization of existing assets is wide and challenging (Barbero et al., 2021), when digitization processes or digital renovation workflows are a priority (Olawumi et al., 2019), as briefly outlined in paragraph 1.1.

At European level, several funded projects (P2Endure, NetUBIEP, BIM-SPEED, BIMEET, BIM4EEB, BIMplement, BIM4REN) or Task Groups (BIM4SMEs, theBIMHub) and current research avenues under the Horizon Europe programme are pursuing the same goal.

The Emilia-Romagna Region promotes and supports the building regeneration process through public and private initiatives. Among the ongoing research in the region, we can highlight the eBIM project and the InSPiRE project (PORFESR 2014-2020), aiming at defining protocols for the knowledge of the built heritage through the integration of diagnostic data into platforms, and at integrating enabling technologies within building components to track their deterioration, pursuing the objective of predictive maintenance. The network includes the Emilia-Romagna High Technology Network and the Clust-ER BUILD - Building and Construction, particularly the issues addressed within the Value Chain Innova-CHM - Innovation in Construction and Cultural Heritage Management, including BIM for the knowledge management of materials and technologies.

The region has therefore enabled the implementation of initiatives aimed at fostering civil awareness and promoting the active participation of enterprises in funded projects that match aspects related to technological permeability in production field, through the involvement of the regional research system. 


\section{DEVELOPED METHODOLOGY}

Following the regional strategy, the research aims to suggest a working methodology specifically designed to deal with the digitalisation of the built heritage of the $20^{\text {th }}$ century in EmiliaRomagna by providing guidelines and tools developed ad-hoc in a parametric BIM environment.

The proposed methodology focuses on the drafting of indications concerning the conversion of the digital survey data to a parametric model. These indications are enhanced by a set of parametric tools (Libraries, templates and families) useful for digitising building elements typical of the period and area.

The connection between the digitisation of the building (BIM As-Built) and the enterprise supply chain (Industry 4.0) comes through the development of BIM Smart Packages developed to integrate the various actors' needs in the decision-making process, conveying information at an integrated system level: Problem-Solution Approach, Integrated Solution $(A+B+C)$, System Certification $(A+B+C$ Compatibility and Installation), Lifecycle Warranty.

\subsection{Analysis of the existing building stock in the Emilia- Romagna Region}

The definition of the key criteria on which to articulate the intervention methodology starts from the analysis of the existing built heritage in the region, beginning with the quantitative analysis, through the data gathered in the ISTAT ${ }^{1}$ reports and the re-elaborations carried out by CRESME. From this analysis, it was possible to define the number of buildings and their purpose. The assessment showed that the regional heritage comprises just under one million units $(943,307)$ and represents $6.5 \%$ of the national stock. Of this sample, $87 \%$ is made up of buildings intended for residential use (higher than $84.3 \%$ of the national data) and $13 \%$ non-residential $(15.7 \%$ national data). The data analysis also shows a quantitative inhomogeneity in the territorial distribution. Bologna, Modena and Reggio Emilia provinces are more urbanized than the other provinces, although they keep a constant ratio between residential and productive buildings.

This analysis was followed up with an in-depth analysis of the construction period. The data relating to the construction period is essential to evaluate the longevity of construction elements and their state of maintenance.

A major part of the buildings in the region were built before the First World War and in the period between the end of the Second World War and the 1980s. From the early 1980s to the present day, we can record a significant decrease in new buildings (Cresme, 2021).

From this analysis, it is possible to gather indicators concerning the longevity of buildings, the life cycle of components (ISO 15686), and the maintenance cycles carried out and to be planned. These indicators, implemented in the BIM modelling including constriction elements, are essential in the renovation planning phase.

\subsection{Analysis of construction technologies}

The technological-structural features of buildings were analysed to understand how the building process evolved during the 20th century. From a structural point of view, it is evident that there has been a gradual shift from the almost exclusive use of

$1 \mathrm{http} / / /$ dati-censimentopopolazione.istat.it/index.aspx and https://www.istat.it/it/files/2014/08/Nota-edifici-eabitazioni_rev.pdf construction technologies considered "traditional" (e.g. loadbearing masonry structures) at the beginning of the century to the increasingly widespread use of reinforced concrete, which, in the 1970s corresponded the load-bearing masonry system in terms of the number of constructions. This period also marks an increase in the use of construction technologies such as steel and wood, previously not widely used for structural purposes.

This technological transition took place throughout the twentieth century, driven by the transition from the handcrafted process to the industrial process (Trivellin, 1998). The industrialisation of the building component manufacture process also led to the standardisation of components (Daglio and Ginelli, 2021).

The industrialisation of processes and applied research led to increased technological performance of materials and construction elements. As a result, the morphology of technological units also changed, and the concept of prefabrication was adopted extensively in construction (Fig. 2). In the process of intervention on the built environment, we work on stratified fabrics, composed of elements that can result from both craft and industrial processes, assembled on-site or prefabricated with performance differences that can be very different. Following the concept of the life cycle (Ingrao et al., 2018) of a building component, the construction period significantly impacts the maintenance of the operating features.

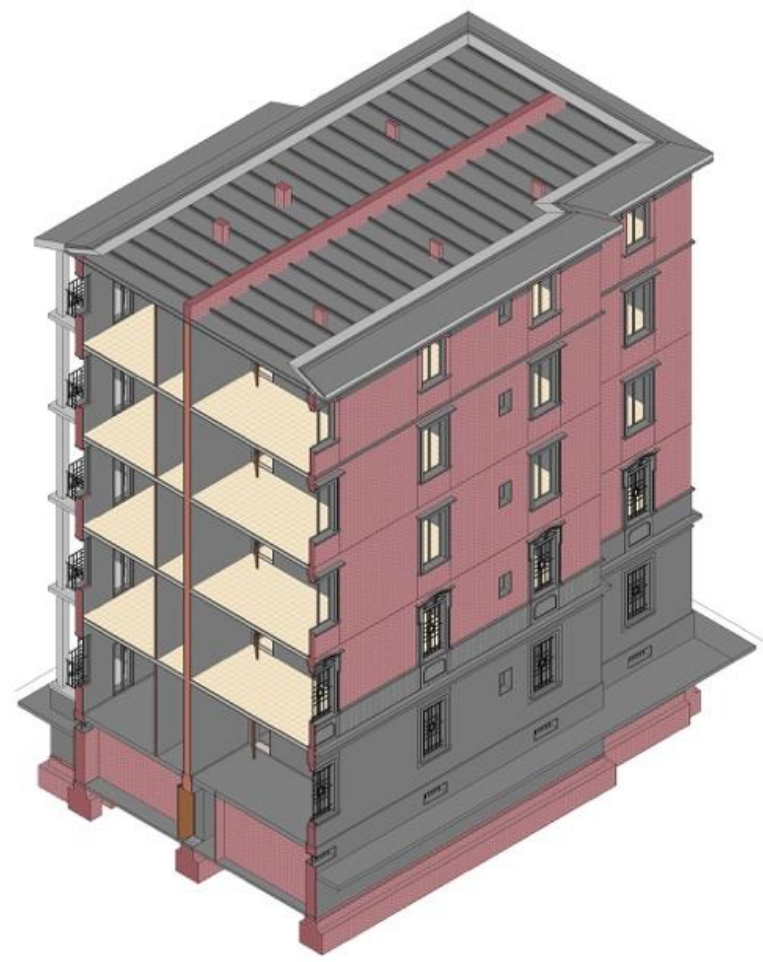

Figure 2. The cutaway model shows construction elements characteristic of the period, such as external decorations and windows with peculiar features.

\subsection{Ownership of buildings}

A further feature to be taken into account is the ownership of the property. The Italian real estate market is historically known to be particularly fragmented, with the percentage of individual owners among the highest in Europe (Muzzicato et al, 2008). This peculiarity brings both positive and negative aspects in terms of refurbishment. While the owner/resident is particularly 


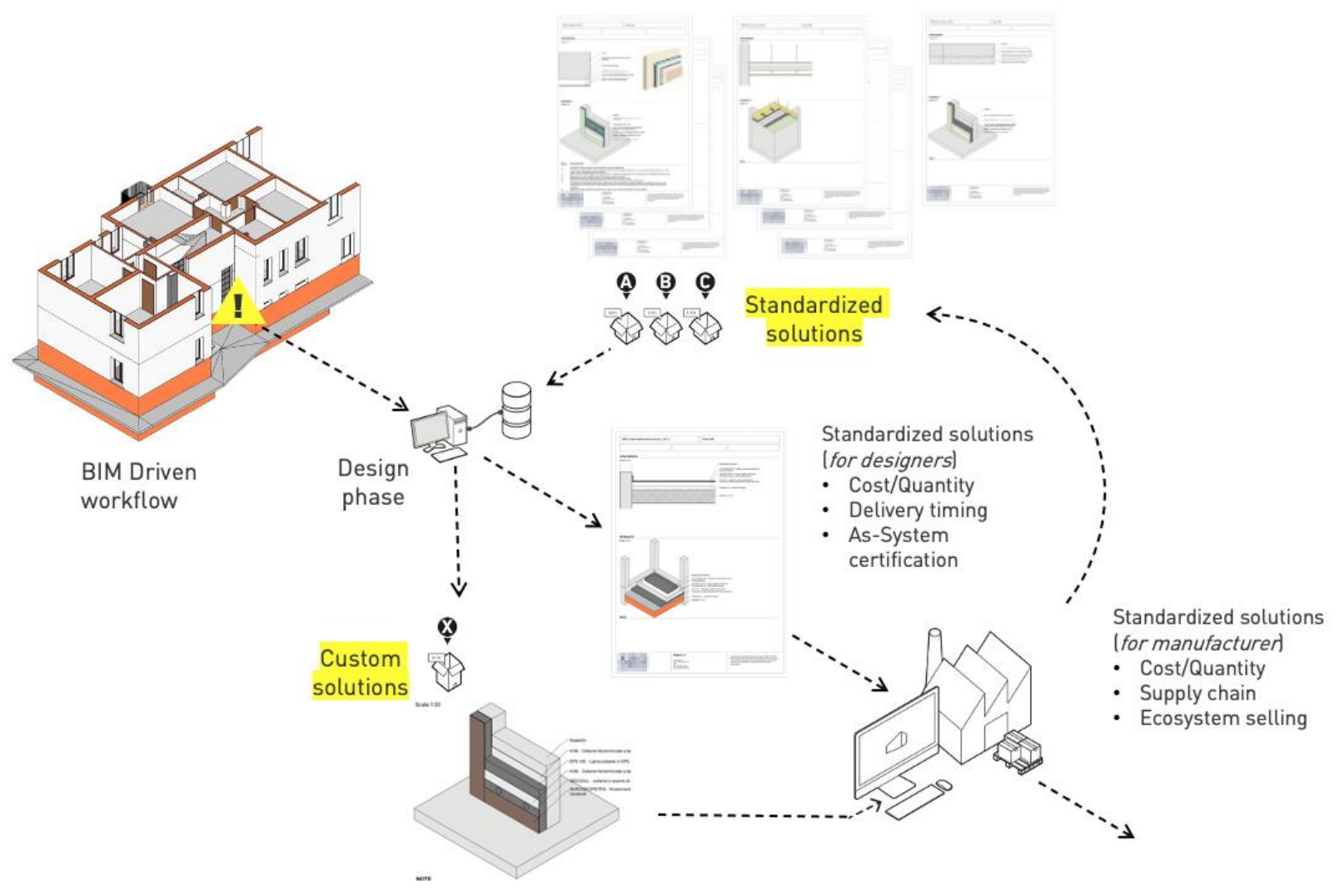

Figure 3. BIM workflow schematization. It is possible to identify and implement one of the standardized solutions during the project phase or to produce a custom one. The manufacturer's smart packages are validated and implemented in the system.

careful about the maintenance of the residential building, it also makes it particularly challenging to deal with multi-family buildings. In order to keep the research development within a manageable timeframe, it was decided to focus the selection process on buildings that were as less fragmented as possible. This aspect has led to considerable benefits in terms of authorisations since it was possible to approach a single stakeholder.

\subsection{Identification of case studies and accessibility verification}

The analysis made it possible to identify the main criteria to focus on the following phases of the research development. In order to achieve a representative sample of buildings, exhaustive enough in terms of construction technology and size, it was decided to identify a set of buildings to be used as case studies by selecting them among those available.

The buildings to be used as case studies were chosen from those managed by the Azienda casa Emilia-Romagna (ACER) of the Province of Bologna. ACER is a public economic body that deals mainly with real estate management.

Buildings can be owned by ACER itself, the municipality, or other bodies. ACER operates according to economic, energy and social sustainability criteria by intervening on buildings mainly for residential purposes (Fanzini et al., 2020).

The particular attention that ACER pays to the energy efficiency improvement of the buildings (Fava and Maranghi, 2021) and the availability of an internal core of maintenance services focused on the technological innovation of the processes has made ACER an ideal partner for identifying case studies.
A representative sample in the urban context has been selected, using as selection criteria the size of the building, its location and the construction period.

The case studies have been identified among those present in the ACER Bologna heritage, which present such constructive and dimensional characteristics to cover a relevant part of the issues to be exhaustively addressed. Of these case studies, the issues related to the external envelopes will be deepened, as these are more involved in decay issues (Lo Turco et al., 2017) and energy efficiency measures.

\section{DIGITISATION OF INTERVENTION ON EXISTING BUILDINGS. THE SHARED PROCESS}

Following the analysis phase, a set of key indicators for the intervention on the existing buildings was defined.

The identified needs are related to the building owner (or manager), professionals involved in the intervention design (architectural and structural designer, building process managers), operational workers (construction companies and contractors) and components producers (building product manufacturers).

One of the research objectives is to involve all actors in developing and managing the BIM model.

The BIM methodology is considered a widely diffused standard for new constructions. If applied to the intervention on the built environment, the path towards an extensive adoption is still far to come.

Small and medium-sized companies, or those that are less open to technological advances, struggle to organise themselves in such a way as to find and employ the necessary skills to implement a BIM workflow. 
If the design world is already oriented towards this transaction fairly uniformly, this cannot be said for the other stakeholders. A quite significant difference in technological receptiveness to computer-aided project management (Travaglini et al., 2014) is quite evident when the different players are examined.
Since the main focus of the work was on the building envelope, it was decided to develop envelope-oriented packages. However, it was also decided to include a minor number of interior renovation packages in the first development phase. This second line of development was created to verify that the

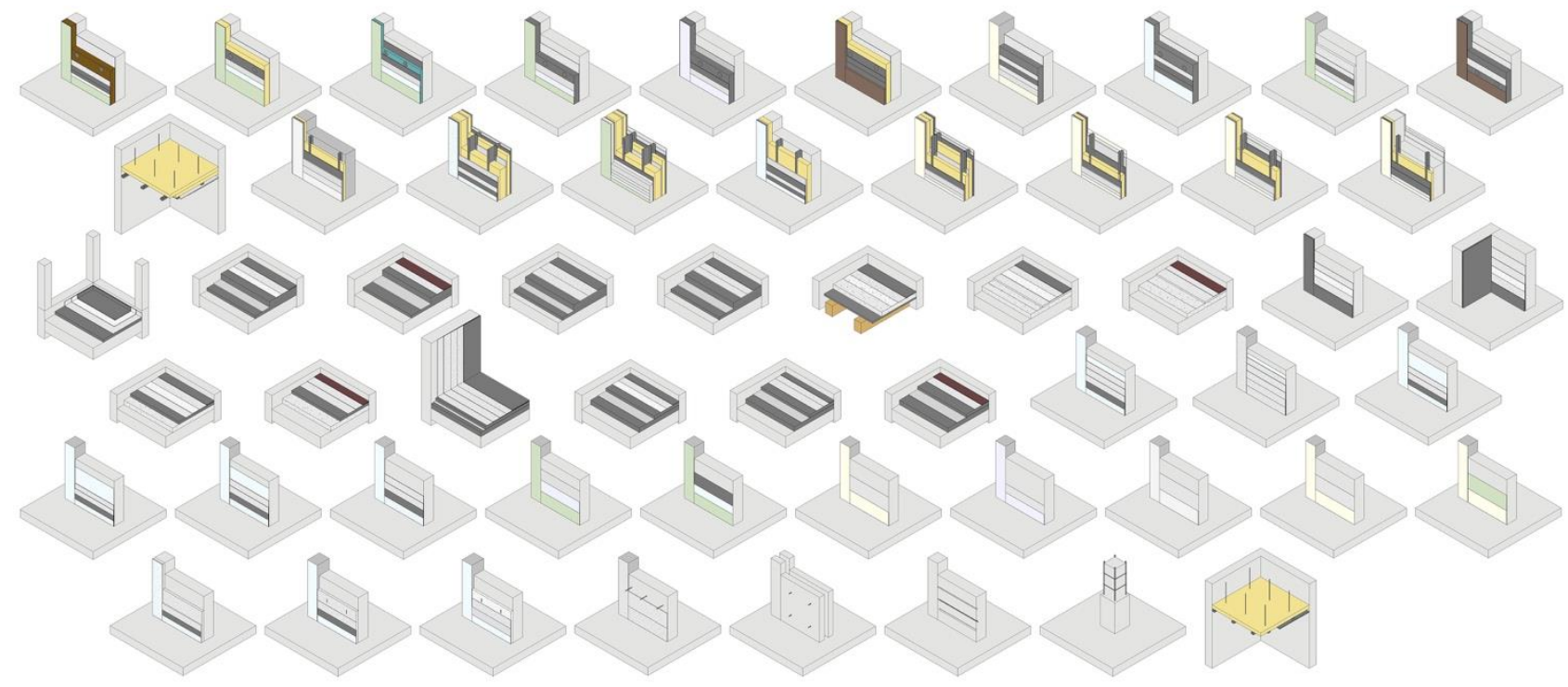

Figure 4. Overview of the first batch of smart packages produced. These represent the sixty parametric packages related to the solutions identified and developed to operate in the six areas of intervention.

The main challenge is the complexity of the process managed through BIM, which requires a planned, coordinated, and synchronised effort from all the involved actors.

To foster an inclusive approach to the process, the research methodology proposes simplified tools and procedures (Fig. 3), designed to allow a gradual transition into the world of parametric BIM methodology.

\subsection{The "Smart packages"}

The research investigates the topic of digitisation through the BIM methodology of a sample of digital "technological systems". These technological systems are layered materials designed to solve specific intervention problems in the existing built environment (Becerik-Gerber et al., 2012).

The product packages represent a solution developed by the manufacturer to provide the most effective product system, considering the compatibility between the individual elements of which they are composed.

The problem-solution approach means that a range of sufficiently comprehensive developable solutions can be identified to cover a significant amount of the designers' requirements.

\subsection{Project scalability}

The packages represent an initial development batch to start covering the most statistically recurrent intervention cases.

Therefore, it was decided to define a first batch of sixty technological solutions (Fig. 4), divided into six macro-areas of intervention.

The areas of development concern: thermal insulation of the envelope, surface finishes, dehumidification packages, consolidation packages, drywall and the installation of coatings. features implemented in the development phase were exhaustive and would guarantee the scalability and application of the methodology in other areas.

Given the number and variety of materials involved in creating the packages and the possible variables of each material, it was decided to integrate an index file (XML) into the development process that records and indexes the reference values, simplifying the data entry phase and their updating.

The values that characterise the materials are to be considered variables; these values need to be updated periodically, following the changes made during production.

The project structure takes into account further developments, implementing the possibility of modifying and expanding the information included.

The workflow for the information layer is vertically structured, i.e. the information about the individual materials and the rules that aggregate them into packages are indexed by the manufacturer, who transfers them to the operator who deals with their parameterisation in the BIM environment. The created packages are validated and available to users through the manufacturer's web portal or specialised portals.

These packages are made uniquely identifiable through coding consisting of the package's name, the date of development and the version (e.g. FBIM_A4_GY01_2022v1).

\subsection{Package composition}

The file supplied to the user (Smart package) is a compressed archive named by its coding.

The compressed file contains three elements (Fig. 5): a PDF document in A4 layout showing the information contained in the parametric file; the parametric BIM file containing the developed family and the material library. 
BIM Smart Package library

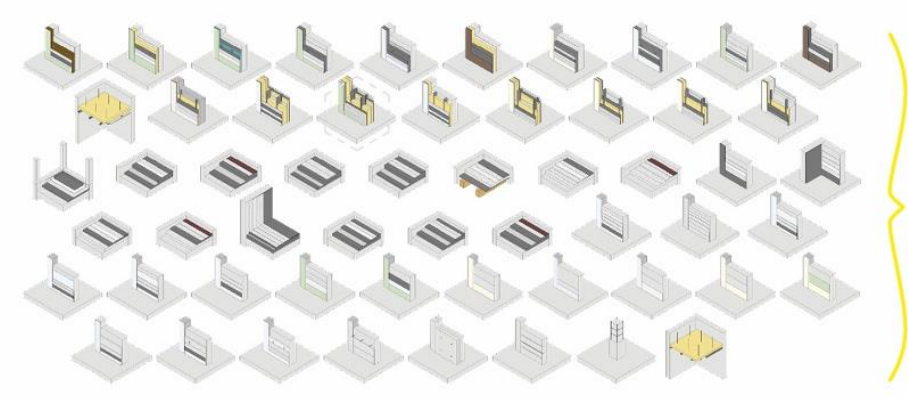

Selected solution

PDF Datasheet

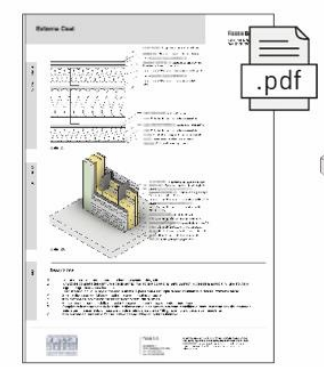

BIM Package

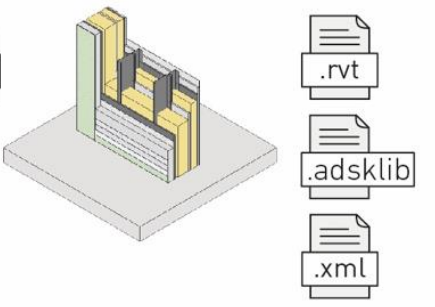

Figure 5. End-user identifies the solution that best meets his needs through the manufacturer's portal. The system allows downloading the compressed archive with the selected data (smart package) and displays additional information about individual products and certifications.

The PDF document (Fig. 6) is used as a synoptic index, allowing a quick overview of the contents of the package without having to open the file within the BIM software.

The hierarchical composition of the contents works on the principle of successive levels of detail. It starts with the extended title of the package in which the function for which it was developed is identified. At the same level, the unique coding of the file is displayed with an indication of the development version.

The next level shows the two-dimensional stratigraphy represented on a scale of 1:5, in which the names of the products inserted are shown in order of application.

The in-depth view continues with a representation in axonometric cut-out (scale 1:10/20). A sample of one metre by one metre is displayed in which the materials making up the package are cut out in succession to illustrate their composition. This view also includes accessory elements shown in a simplified way, such as fixing elements for insulating boards.

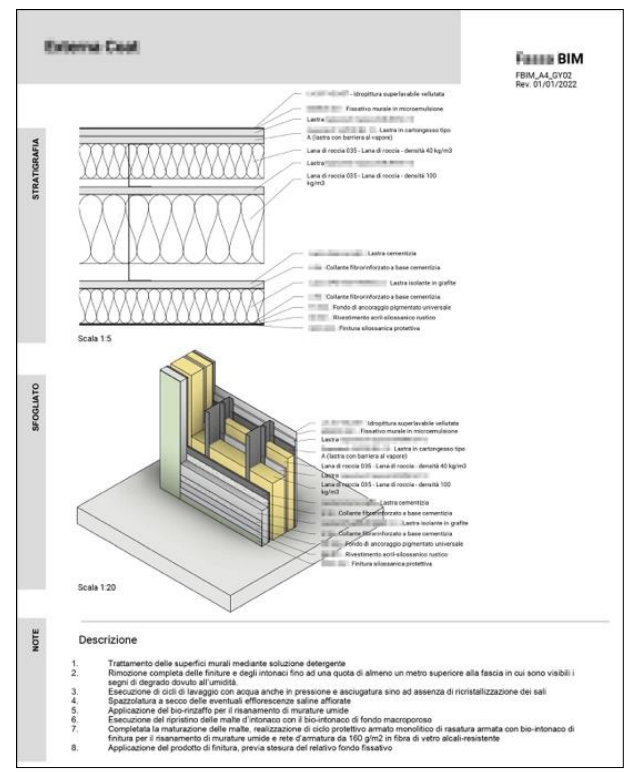

Figure 6. The PDF layout aggregates and indexes the information. This document collects information about the materials that create the stratigraphy. The composition of the smart package is displayed in both two-dimensional and axonometric views.
The last level is made up of a notes field. The package description is shown in text form, as well as the application procedure and the indications provided by the company in terms of existing substrate preparation and potential incompatibilities.

The parametric file contains the developed family, together with the material library and the nested families developed for the correct composition of the package.

For instance, a package made up of rigid insulating panels will also include a series of nested families that represent the required mechanical supports. On the other hand, a package created to represent insulating drywall will include the boards and the underlying metal profiles.

The materials library is the file that contains all the digitised materials. Instead of fragmenting it, it has been chosen to create a single library to detach the library from the single package. In this way, the material library file can also be used stand-alone, providing operators with a tool that is not linked to individual ready-made solutions.

The digitised materials include the commercial name, descriptive information and manufacturer information. Graphic information representing the material is also included, along with physical and thermal properties where available.

The project identification code is always reported within each document, package, family, or material, with the web link to the reference portal. The code for the aggregated package is shown where available, with the relative update date and version.

\subsection{Updating of information}

The information is updated in a semi-automated manner using an XML import script. The XML format was chosen because of the possibility of extracting the information directly from the company's ERP (Enterprise Resource Planning) system. As a further development, the possibility of creating a dynamic link via database has been planned.

The update phase ends with exporting and publishing packages, renamed to the latest version.

Due to the kind of changes that the manufacturer can make and their frequency, it is unnecessary to provide end-users with a record of previous versions. The release history is always stored by the developer and may be made available if required in the future.

\subsection{Development and software ecosystem}

The proposed system is organised in several consecutive development phases. The aim is to provide tools that can be 
immediately adopted by investing in technologies and processes with high TRL (Technology Readiness Level). Once the users are familiar with the BIM working methodology, it will be possible to start the following phases characterised by the increase of the offer (number of packages), the development for different platforms (Archicad, Allplan, Tekla, etc.) and higher process automation (Dynamo, Python, etc.).

In the first phase, the packages are developed exclusively for Autodesk Revit, which covers a considerable part of the market share of the applications currently used in the region.

The dialogue between the Enterprise Resource Planning platform (ERP), in which the product datasheets including all information and characteristics are created, and the BIM platform takes place in a first phase through export in XML format. This choice is due to the need to simplify the content update process.

The created materials (see section 4.3) are grouped and compressed in a digital archive and made available to the enduser through a duly developed section within the company website.

The files are accessible through a login, allowing the user to record the downloaded solutions. This helps to check quickly for updates on previously downloaded packages.

Proposed solutions are indexed according to the technological system to which they belong. A specific function of the web portal manages the link between the selected BIM package and the related technical documentation developed by the company (Data Sheet, Application Manual, Certifications).

\section{RESULTS AND DISCUSSION}

Through the development of study models, the research aims to develop digital tools useful for the digitisation of the existing built environment. Whether procedural, library elements or execution methods, these tools can be an added support for those stakeholders who are about to carry out an intervention based on a BIM workflow.

The integration of protocols and tools that simplify the aspects of converting the data from the integrated digital survey to parametric modelling can contribute to foster technological permeability in an environment historically not very receptive to the digitisation of processes.

The development of BIM Smart Packages, which combine the needs of all the actors involved in the refurbishment process and those who have to produce and trade integrated solutions, can increase stakeholder interest in investing in the digitisation of the intervention process.

The research aims to promote an integrated methodology based on digital tools to support technicians working on existing buildings using a BIM methodology. The methodology was designed and developed to operate on a specific field of intervention, trying to combine the aspects related to the digitalization of the building (As-Built) with the needs of the refurbishment intervention in an integrated supply chain perspective. Owners, designers, contractors and manufacturers represent the chain of stakeholders at which the project is aimed.

The XX century buildings redevelopment is not only an essential target for the Emilia-Romagna region, but it also covers the main needs to meet the goals of emission reduction, energy saving and use of renewable energy sources throughout the building life cycle.

Therefore, the issue of digitisation processes or digital renovation workflows is a priority toward an efficient information and data collection (technical specifications, sensors, etc.), data management, and data archiving, conservation and sharing, to make the redevelopment process easily manageable and more effective.

The research also explores the growing trend of manufacturing companies to make their products available in IFC - Industry Foundation Classes models.

The research ambition is to contribute to the definition of a shared ecosystem that will require the effort of both designers and manufacturers, triggering new forms of accessibility to data aggregated to 3D models (interoperable and open access) for an inter-sectoral and interdisciplinary use of digital tools.

\section{ACKNOWLEDGEMENTS}

The research is part of the IDAUP - International Doctorate in Architecture \& Urban Planning, XXXV cycle, consortium between the University of Ferrara, Department of Architecture, Polis University of Tirana and, as Associate Members, the University of Minho, Guimaraes (Portugal), Slovak University of Technology, Institute of Management, Bratislava (Slovakia) and University of Pécs / Pollack Mihaly Faculty of Engineering and Information Technology (Hungary). The research is being developed thanks to the grant funded by the Emilia-Romagna Region. Call Alte Competenze per la ricerca, il trasferimento tecnologico e l'imprenditorialità (Delibera di Giunta Regionale n. 39 del 14/01/2019), entitled: Application of integrated digital tools for surveying, diagnostics and BIM modelling to support innovation of components and systems, products and services with high added value for the intervention on existing buildings. Doctoral fellowship approved by the Deliberation of the G.R. n. 462/2019 "Approval of the research training projects presented on the basis of the Call approved by its own resolution n. 39/2019. POR FSE 2014/2020" Ref. PA 2019-11299/RER CUP F75J19000440009.

\section{REFERENCES}

Achille, C., Lombardini, N., \& Tommasi, C., 2018. BIM and Cultural Heritage: Compatibility Tests on Existing Buildings. In Achille, C., Lombardini, N., and Tommasi, C., Contemporary Strategies and Approaches in 3-D Information Modeling. IGI Global, Hershey, pp. 1-26.

Barbero, A., Del Giudice, M., Ugliotti, F. M., \& Osello, A., 2021. BIM model uses through BIM methodology standardization. In Semenov, V., and Scherer, R.J. (Eds.), ECPPM 2021 - eWork and eBusiness in Architecture, Engineering and Construction. CRC Press (Taylor \& Francis), Boca Raton, pp. 35-41.

Becerik-Gerber, B., Jazizadeh, F., Li, N., \& Calis, G., 2012. Application areas and data requirements for BIM-enabled facilities management. Journal of construction engineering and management, 138(3), 431-442.

Bianchini, C., Attenni, M., \& Potestà, G., 2021. Regenerative Design Tools for the Existing City: HBIM Potentials. In Andreucci, M.B., Marvuglia, A., Baltov, M. and Hansen, P. (Eds.), Rethinking Sustainability Towards a Regenerative Economy. Springer, Cham, pp. 23-43.

Carnevali, L., Lanfranchi, F., \& Russo, M., 2019. Built information modeling for the $3 \mathrm{D}$ reconstruction of modern railway stations. Heritage, 2(3), 2298-2310.

Cresme, 2021. Il recupero e la riqualificazione energetica del patrimonio edilizio: una stima dell'impatto delle misure di 
incentivazione,

https://www.camera.it/temiap/2020/11/26/OCD177-4699.pdf

(Last accessed: Nov 2021).

Daglio, L., \& Ginelli, E., 2021. L'eteronomia delle tecniche costruttive nel settore delle costruzioni in Italia. Appunti per le cose da fare. Techne, 21, 145-153.

Daniotti, B., Bolognesi, C. M., Lupica Spagnolo, S., Pavan, A., Signorini, M., Ciuffreda, S., ... \& O'Sullivan, D., 2021. An Interoperable BIM-Based Toolkit for Efficient Renovation in Buildings. Buildings, 11(7), 271.

European Commission, 2021. A European Green Deal. Striving to be the first climate-neutral continent, https://ec.europa.eu/info/strategy/priorities-2019-

2024/european-green-deal_en (Last accessed: Jan 2022).

European Commission, 2019. Cooperation on advancing digitisation of Cultural Heritage, Digital Day 2019, Brussels ec.europa.eu/digital-single-market/en/news/eu-member-statessign-cooperate-digitising-cultural-heritage (Last accessed: Oct. 2021).

Fanzini, D., Rotaru, I., De Cocinis, A., Achille, C., \& Tommasi, C., 2020. Collaborative Reactivation of the Built Environment: A Socio-cultural Perspective. ACTIO Journal of Technology in Design, Film Arts and Visual Communication, (4), 18-25.

Fassi, F., Achille, C., Mandelli, A., Rechichi, F., \& Parri, S., 2015. A New Idea of BIM System for Visualization, Web Sharing and Using Huge Complex 3d Models for Facility Management. 6th International Workshop on $3 D$ Virtual Reconstruction and Visualization of Complex Architectures, 3D-ARCH 2015, pp. 359-366.

Fava, F., \& Maranghi, E., 2021. Rigenerare attraverso la casa: analisi e prospettive a partire dall'esperienza delle Aziende casa. Archivio di Studi Urbani e Regionali, 130/2021, pp. 7899. 10.3280/ASUR2021-130005.

Horizon Europe strategic plan 2021-2024, European Commission.

https://ec.europa.eu/commission/presscorner/detail/en/ip_21_11 22 (Last accessed: Dec. 2021).

Grilli, E., \& Remondino, F., 2019. Classification of 3D digital heritage. Remote Sensing, 11(7), 847.

Grilli, E., \& Remondino, F., 2020. Machine learning generalisation across different $3 \mathrm{D}$ architectural heritage. ISPRS International Journal of Geo-Information, 9(6), 379.

Harirchian, E., Kumari, V., Jadhav, K., Raj Das, R., Rasulzade, S., \& Lahmer, T., 2020. A machine learning framework for assessing seismic hazard safety of reinforced concrete buildings. Applied Sciences, 10(20), 7153.

Ingrao, C., Messineo, A., Beltramo, R., Yigitcanlar, T., \& Ioppolo, G., 2018. How can life cycle thinking support sustainability of buildings? Investigating life cycle assessment applications for energy efficiency and environmental performance. Journal of cleaner production, 201, 556-569.
Jouan, P., \& Hallot, P., 2020. Digital twin: Research framework to support preventive conservation policies. ISPRS International Journal of Geo-Information, 9(4), 228.

La Russa, F.M., \& Santagati, C., 2020. Historical SentientBuilding Information Model: A Digital Twin for the Management of Museum Collections in Historical Architectures. The International Archives of Photogrammetry, Remote Sensing and Spatial Information Sciences, XLIII, 755762.

Lo Turco, M., Mattone, M., \& Rinaudo, F., 2017. Metric survey and BIM technologies to record decay conditions. International Archives of the Photogrammetry, Remote Sensing and Spatial Information Sciences, 42(5/W1), pp. 261-268.

Muzzicato, S., Sabbatini, R., \& Zollino, F., 2008. Prices of Residential Property in Italy: Constructing a New Indicator. Bank of Italy Occasional Paper No. 17, http://dx.doi.org/10.2139/ssrn.1287629.

Olawumi, T. O., \& Chan, D. W., 2019. Building information modeling and project information management framework for construction projects. Journal of Civil Engineering and Management, 25(1), 53-75.

S3, 2021. Strategia di ricerca e innovazione per la specializzazione intelligente 2021-2027. https://fesr.regione.emilia-romagna.it/s3/s3 (7 December 2021).

Teruggi, S., Grilli, E., Fassi, F., \& Remondino, F., 2021. 3D surveying, semantic enrichment and virtual access of large cultural heritage. ISPRS Annals of the Photogrammetry, Remote Sensing and Spatial Information Sciences, 8, 155-162.

Travaglini, A., Radujković, M. \& Mancini, M., 2014. Building Information Modelling (BIM) and Project Management: a Stakeholders Perspective. Organization, technology \& management in construction, 6 (2), 1001-1008. https://doi.org/10.5592/otmcj.2014.2.8

Trivellin, E., 1998. Storia della tecnica edilizia in Italia: dall'unità ad oggi (Vol. 29). Alinea Editrice. Pp. 135-152 